\title{
SINKHOLE INVESTIGATION AFTER HURRICANE IRMA
}

\author{
Ryan Shamet
}

University of Central Florida

12800 Pegasus Drive

Orlando, Florida,32816,United States,rshamet@knights.ucf.edu

Moataz Soliman

University of Central Florida

12800 Pegasus Drive

Orlando, Florida,32816, United States, moatazhs@knights.ucf.edu

\section{YongJe Kim}

University of Central Florida

12800 Pegasus Drive

Orlando, Florida, 32816, United States,yongje.kim@knights.ucf.edu

\author{
Timothy Copeland \\ University of Central Florida \\ 12800 Pegasus Drive \\ Orlando, Florida, 32816, United States, trcopeland10@knights.ucf.edu
}

Boo Hyun Nam, Ph.D.

University of Central Florida

12800 Pegasus Drive

Orlando, Florida, 32816, United States, boohyun.nam@ucf.edu (corresponding)

\begin{abstract}
In September 2017, Hurricane Irma made landfall on the state of Florida. This extreme weather event produced an average of 20-40 centimeters of rainfall across the state. In the following weeks, at least 30 new sinkholes were reported throughout the affected area. An investigation of the sinkhole sites where openings occurred in the middle of a roadway, was carried-out. Multiple cone penetration tests (CPT) were performed at those collapsed sites. In this paper, a comprehensive case study of a sinkhole collapse is presented. First, a hydrogeological assessment on the sinkhole site was conducted. Second, CPT data were investigated. Particularly, a sinkhole evaluation index, the Sinkhole Resistance Ratio (SRR), was used to evaluate the sinkhole vulnerability in the collapsed site. Lastly, a finite element (FE) based analyses was employed to further investigate the effect of precipitation on sinkhole stability. The CPT results were used to estimate soil type and strength parameters as inputs to the FE model. Based on the results of multiscenario simulations, it is believed that the main triggering mechanism in the US 441 site was a rapid increase of hydraulic gradient (or seepage velocity) that accelerated
\end{abstract}

soil erosion and piping. In addition, the effect of raised groundwater table on the failure condition of overburden soil layer may not be significant.

\section{Introduction}

Sinkholes are known as a naturally occurring hydrogeological process that causes life-threatening events and can cause significant structural losses. Economic loss due to sinkholes is significant. For example, the economic damage caused by sinkholes in the United States is estimated to be more than $\$ 300$ million per year ( $\mathrm{Ku}$ niansky et al. 2016). According to the Florida Office of Insurance Regulation, the total reported insurance claims in Florida increased from 2,360 in 2006 to 6,694 in 2010, costing approximately $\$ 1.4$ billion (Florida office of insurance and regulation 2010).

Many researchers have conduced geological and hydrogeological studies on karst sinkholes (Beck 1986; Waltham et al. 2005; Brinkmann et al. 2008; Gutierrez et al. 2014; Xiao et al. 2016). In the meantime, engineer- 
ing-based studies have been performed to understand geotechnical engineering behaviors of sinkholes, including sinkhole physical modeling (Perez et al. 2017), sinkhole numerical analyses and stability evaluation (Drumm et al. 2009; Soliman et al. 2018; 2019), and site characterization and vulnerability indexing (Jammal 1986; Foshee and Bixler 1994; Shamet et al. 2017;2018). In addition, a regional-scale sinkhole hazard map of east Central Florida has been also proposed to quantitatively determine the vulnerability of sinkhole occurrence (Kim et al. 2017; 2018). Several researchers have adopted remote sensing techniques such as LiDAR data for sinkhole assessment at large scales (Doctor and Young 2013; Rahimi and Alexander 2013; Kim et al. 2019).

It is known that extreme water events trigger sinkhole formation. For example, Tropical Storm Debby in June 2012 brought a large amount of precipitation and triggered the formation of many sinkholes throughout the state (Kromhout 2017). It is proposed that groundwater flow is a key factor to trigger sinkhole occurrence and the process of internal soil erosion (Xiao et al. 2016). Tihansky (1999) also reported that an increase in surface water due to rainfall events increases the load on subsurface cavities through raising the water level in the surficial aquifer, resulting in greater erosion of overburden soils.

In this paper, one of the post-Irma sinkhole sites, US 441 in Marion County, Florida, is presented as a case study. The case study shows how the sinkhole "reconnaissance" investigation was conducted. This sinkhole investigation includes three key tasks: (1) assessment of hydrogeological factors, (2) in situ subsurface exploration (e.g., CPT), and (3) finite element based numerical analyses.

\section{Background on Hurricane Irma}

Hurricane Irma made landfall in central Florida on September 10, 2018 and produced an average of 20-40 cm of rainfall across the Floridian peninsula. Hurricane Irma had maximum sustained winds of $185 \mathrm{mph}$ for 37 hours. Irma stretched nearly $1100 \mathrm{~km}$ in diameter and affected at least nine US states. Making landfall in southwest Florida as a Category 4 on September 10, Irma was classified as a hurricane from August 31 until September 11. The projected path of Hurricane Irma is shown in Figure 1. Due to this extreme rainfall event, many sinkholes

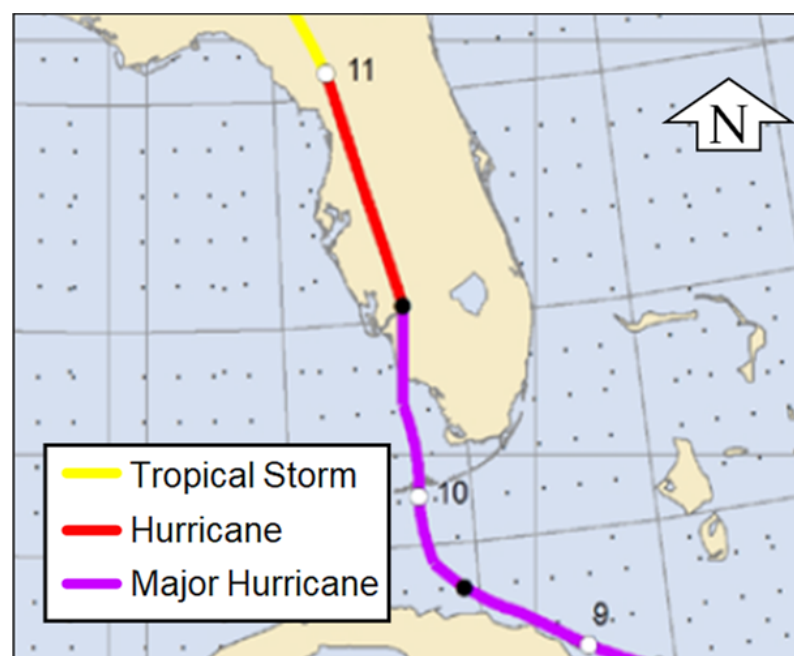

Figure 1. Path of Hurricane Irma (from National Hurricane Center, 2018).

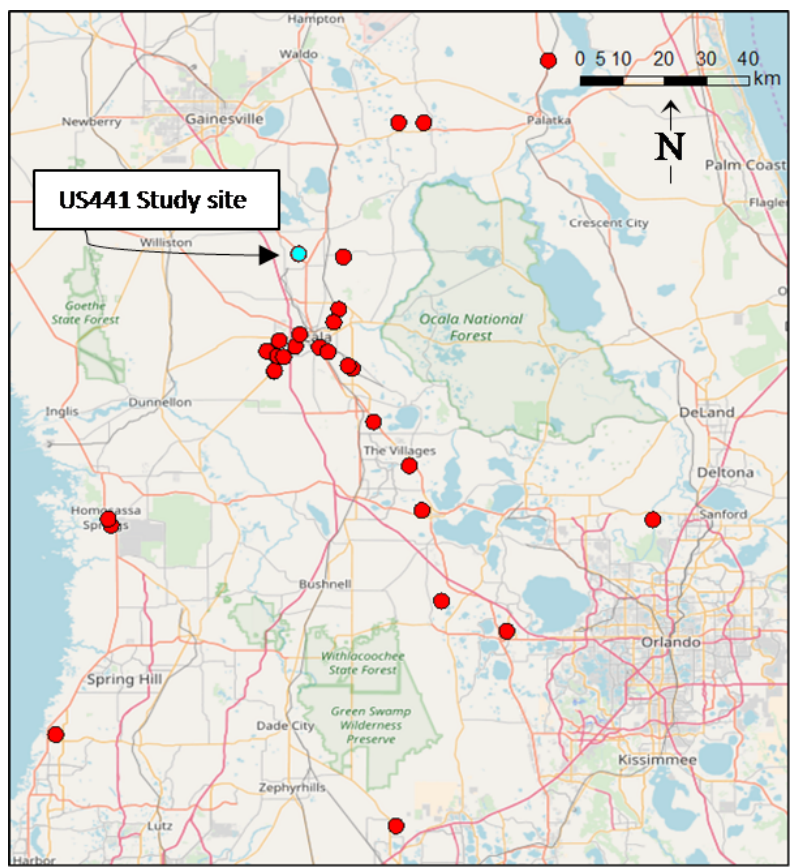

Figure 2. Map of central Florida showing postIrma sinkholes.

were formed. Just within two weeks after Irma, at least 30 sinkholes were reported in the state. Figure 2 presents a map of central Florida showing the locations of those 30 sinkholes that formed after Irma (red circles).

It is hypothesized that the extreme rainfall event triggered by Hurricane Irma significantly impacted groundwater flow conditions (water table rise and increased 
groundwater recharge to the Floridan aquifer), leading to active sinkhole in central Florida. Groundwater wells nearby the US441 sinkhole were investigated and the one in Ocala, FL was selected.

This well location is about $16 \mathrm{~km}$ away from the US 441 site and the well depth is about $47 \mathrm{~m}$. Figure 3 shows the well data of upper Floridan aquifer and the resulting increase during the affected time of the hurricane. Considering a slower respond of Florida aquifer to surface water inputs than a surficial aquifer, the groundwater table of surficial aquifer would have larger increase during Irma. This occurrence may result in a temporary higher head difference between the two aquifers (i.e., larger hydraulic gradient between two aquifer systems).

\section{US441 Post-Irma Sinkhole Investigation}

\section{Methodology}

The research team conducted a post-hurricane investigation on the US 441 sinkhole site with different scales and aspects. As seen in Figure 4, the methodology includes three main tasks: (1) assessment of hydrogeological factors, (2) in situ subsurface exploration (e.g., CPTs), and (3) finite element (FE) based numerical analyses.

First, the hydrogeological assessment at a regional scale was conducted as an initial check prior to the field geotechnical assessment. This initial assessment investigated the regional-scale maps of groundwater recharge, head difference (between surficial and confined aquifers), thickness of overburden layer, and aquitard thickness to understand overall hydrogeological conditions in the surrounding area of the US 441 sinkhole.

Second, a CPT-based subsurface investigation was carried out. After the sinkhole collapse at US 441, a total of 13 CPT soundings were conducted around the collapse point (see Figure 5). CPT sounding profiles were used to evaluate the vulnerability of sinkhole in both a qualitative and quantitative manner. As seen in the CPT sounding profiles (see Figure 5), a sudden drop of cone tip resistance $\left(q_{c}\right)$ in the profile indicates the existence of soil raveling.

Due to the raveling of soils, $\mathrm{q}_{\mathrm{c}}$ becomes extremely low within this zone, generally less than 5 tons per square foot (tsf), which was a rough raveling criterion proposed

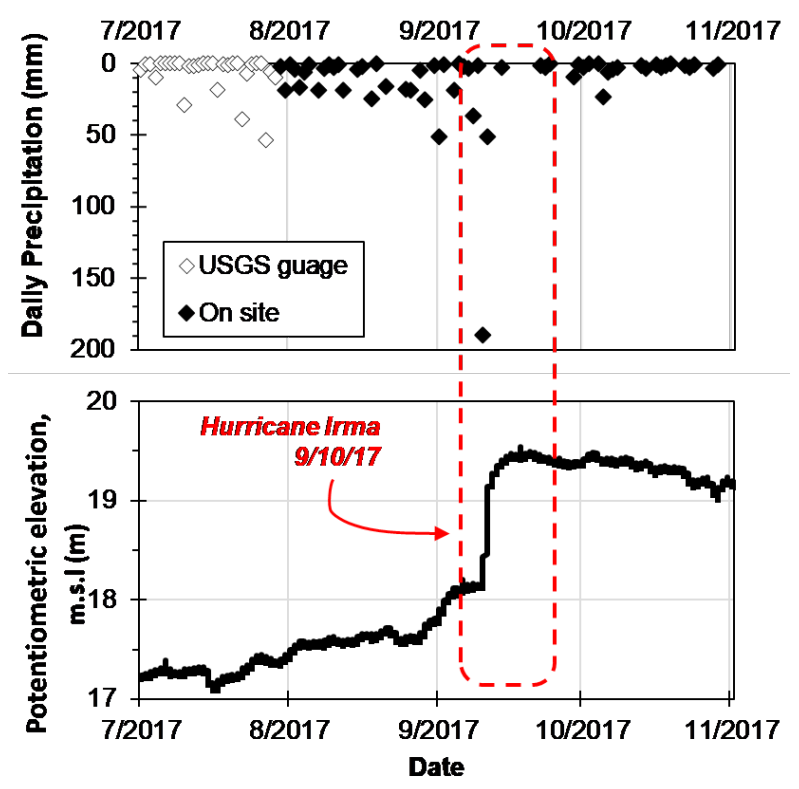

Figure 3. Precipitation and potentiometric elevation trends of Floridan aquifer during time of Hurricane Irma (after USGS 2018).

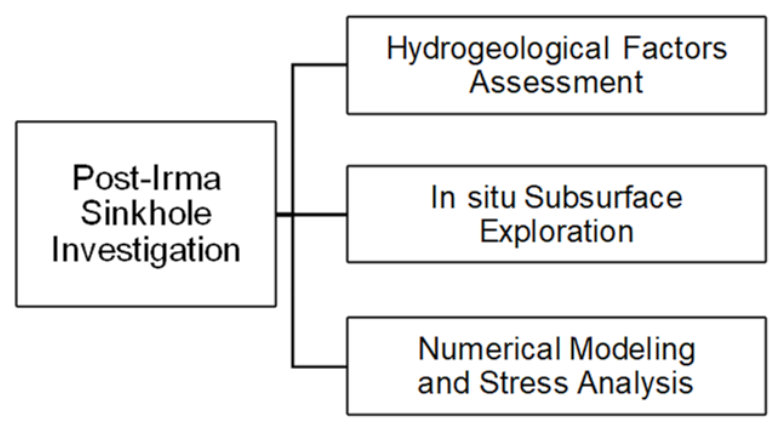

Figure 4. Post-Irma sinkhole investigation tasks

by Foshee and Bixler (1994). As internal soil erosion proceeds, the size of the raveled zone increases while the area of competent overburden soils decreases. A sinkhole vulnerability index, Sinkhole Resistance Ratio (SRR) proposed by Nam et al. (2018), was used to quantify the level of sinkhole vulnerability, due to raveling, within the site.

Lastly, a FE analysis was conducted to further investigate the geo-mechanical behavior of sinkhole formation such as the distribution of stress/strain and $p-q$ stress path. The soil profile, from top to bottom, consists of 2-m medium dense silty sand, 6-m clay, and limestone. 


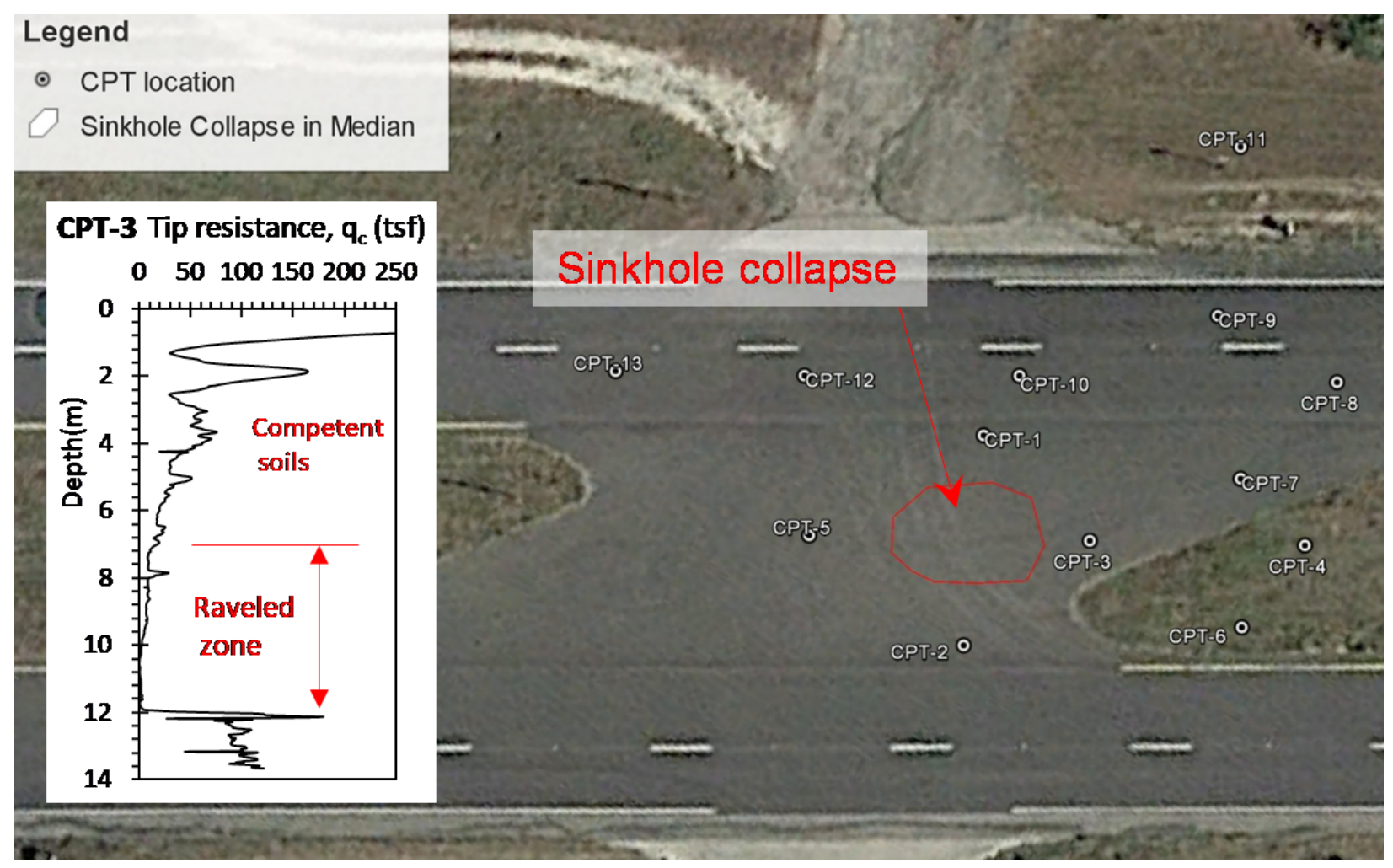

Figure 5. Aerial view showing the CPT locations and a CPT profile showing the raveled zone.

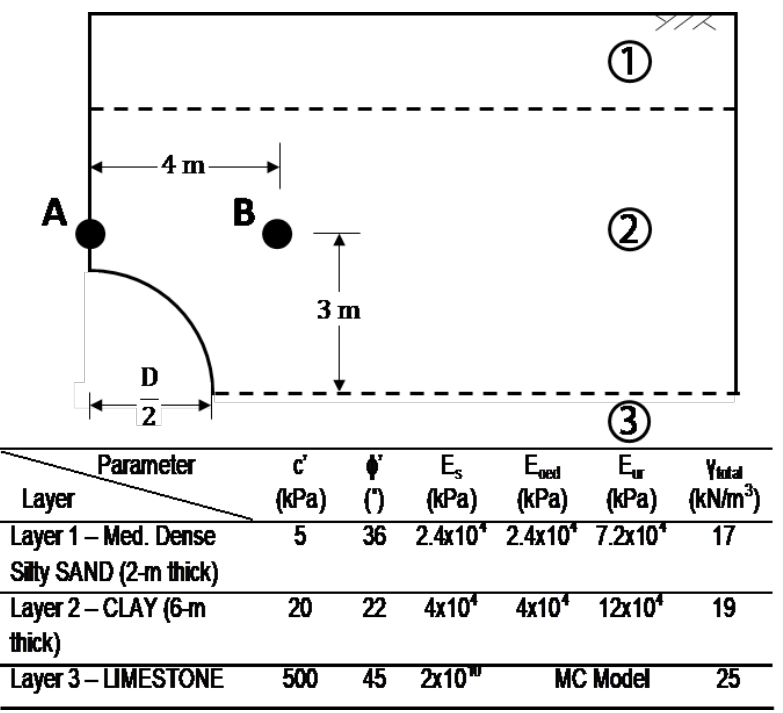

Figure 6. Numerical modeling of the US44 1 site in PLAXIS2D

It is hypothesized that the hurricane raises the surface groundwater table (GWT) and an existing subsurface cavity grows due to the seepage induced soil erosion. Thus, the analysis was aimed at investigating the effects of both variables on the stability of sinkhole. The authors ran the FE simulations with different scenarios of cavity size, overburden layer thickness, and groundwater table elevation. The values of those parameters were varied in the simulations so that critical conditions causing failure were identified. Mohr-Column failure envelope in the $p-q$ diagram was used as a criterion of sinkhole stability. Particularly, the $p-q$ stress paths of two critical points shown in Figure 6 were investigated. For simplicity, the raveled zone was modeled as a half-circular cavity and the hydrostatic condition was employed in investigating the effect of GWT. Figure 6 also shows the FE modeling and initial strength input parameters estimated from correlations using the CPT resistance values (Kulhawy and Mayne 1990) and triaxial test simulations in PLAXIS2D.

\section{Results and Discussion}

\section{Assessment of Hydrogeological Factors}

Hydrogeological conditions of the US 441 site were investigated using the maps of those key hydrogeological factors. The relationship between sinkhole occurrence and those factors can be found in Kim et al. (2018). 

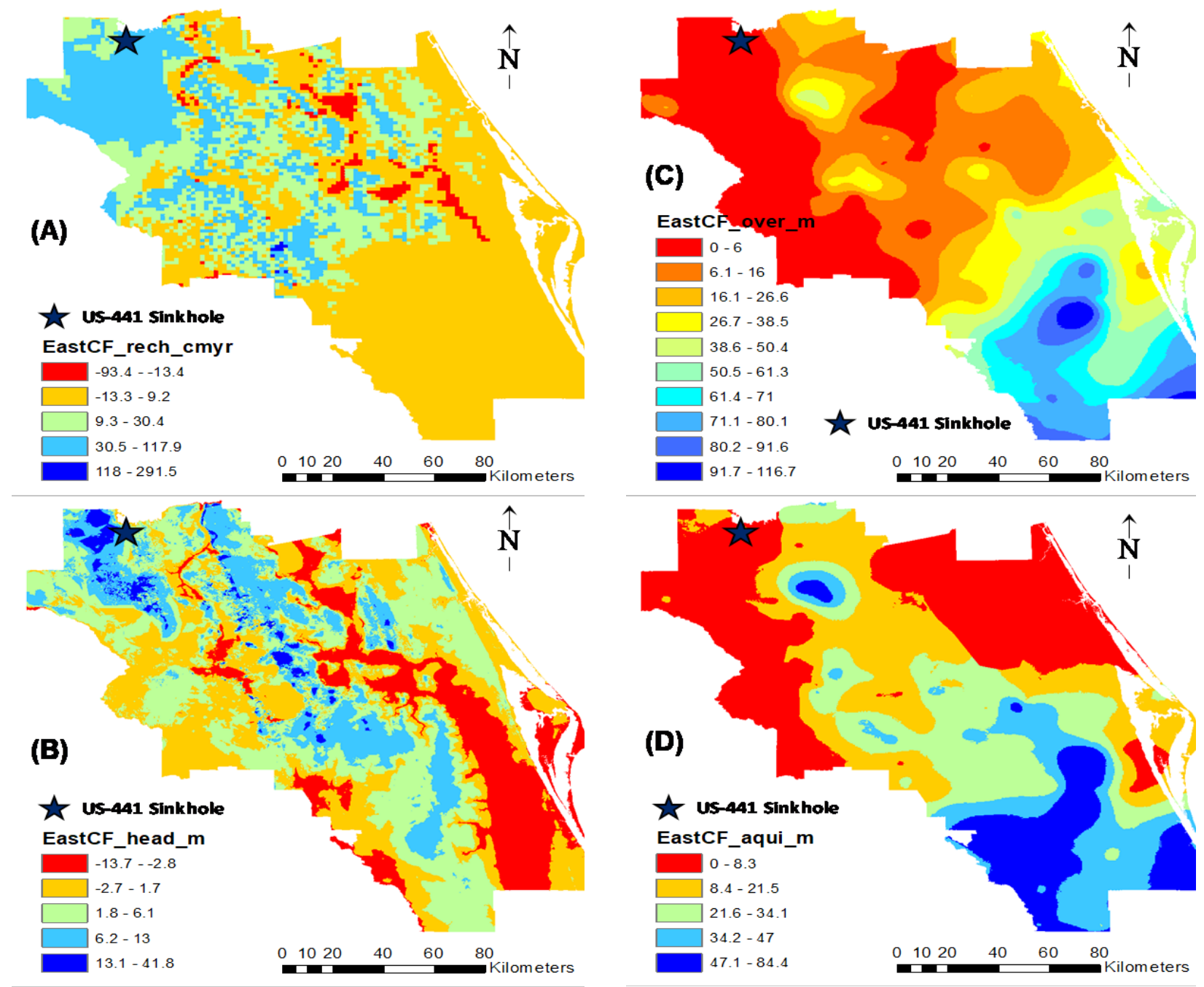

Figure 7. Hydrogeological factor maps showing (A) recharge (B) head difference C) overburden thickness (D) aquitard thickness

The map of each factor (shown in Figure 7) was created and reclassified with the ArcGIS software. As seen in the figure, it is apparent that the US 441 location lies where all hydrogeological conditions are highly favorable for sinkhole. The recharge rate of the study site is quite high with an estimated value between 30 and 118 $\mathrm{cm} / \mathrm{yr}$, favorably eroding the soil into fissured limestone bedrock. The head difference in this location is relatively high with a value of 13 meters; thus, the location has a high potential of internal soil erosion due to groundwater flow. The overburden soil thickness in this area is less than 6 meters and the aquitard layer is either absent or relatively thin (from 0 to $8 \mathrm{~m}$ ). It is believed that groundwater may freely flow or circulate between surficial and upper Floridan aquifer systems that may expedite the dissolution of limestone bedrock.

\section{CPT-based Assessment}

A total of 13 CPT soundings were performed around the collapse. Selected CPT $\mathrm{q}_{\mathrm{c}}$ profiles that indicate the raveling condition are presented in Figure 8. CPTs-1, 2, 3 and 5 were taken at the closest points to the collapse, and the others are relatively distant from the collapse. All CPTs were pushed until a bearing layer was encountered. This stiff layer was assumed to be the weathered limestone through investigation of nearby borings and the visual observation of limestone at the bottom of the sinkhole. As observed through the CPTs, the elevation of encountered weathered limestone "bedrock" significantly varies even within the relatively small area (compare CPT-9 and CPT-13). This is common in a karst area. Although a sinkhole was formed at this site, each CPT location exhibits varying $\mathrm{q}_{\mathrm{c}}$ values along depth, which is commonly 

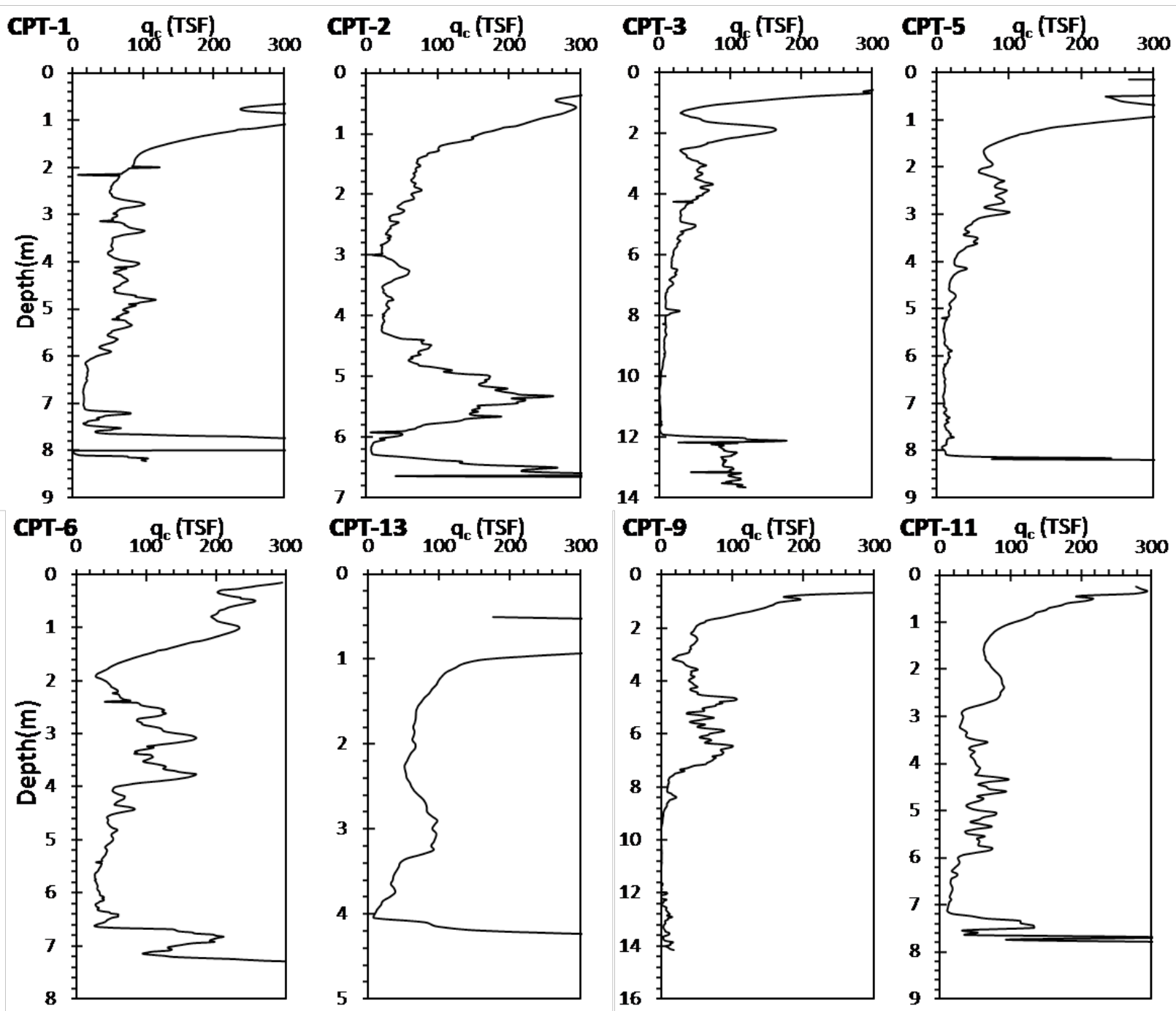

Figure 8. CPT tip resistance ( $q_{c}$ ) profiles around the sinkhole collapse (note: $T S F=t o n / f t^{2}=$ $95.7 \mathrm{kPal}$

observed in karst area. Interestingly, the distance from the collapse does not always correlate with the severity of raveling; for instance, CPT-1 nearby the collapse does not seem as severe as CPT-3 and CPT-5. Rather, CPT-9 shows more severe raveling in the $\mathrm{q}_{\mathrm{c}}$ profile. This observation suggests that raveling can be developed in the form of channels or multiple subsurface voids rather than a sinkhole large cavity. The SRR at each CPT location was computed by the following equation:

$S R R=\left(\frac{t_{\text {over }}}{t_{\text {ravel }}}\right) *\left(\frac{q_{\text {over }}+q_{\text {ravel }}}{100 \sigma_{v}^{\prime}}\right)$
Where:

$\mathrm{q}_{\text {over }}=$ Average measured cone resistance in overburden, competent soils (MPa)

$\mathrm{q}_{\mathrm{ravel}}=$ Average measured cone resistance in raveled zone $(\mathrm{MPa})$

$t_{\text {over }}=$ Depth to encountered raveled zone $(\mathrm{m})$.

$\mathrm{t}_{\text {ravel }}=$ Thickness of raveled zone $(\mathrm{m})$

$\sigma_{v}=$ Effective vertical stress created from overburden soils (MPa)

Figure 9 presents the SRR computed at each CPT location. The authors categorized the SSR values into four categories with different colors, and each CPT location 


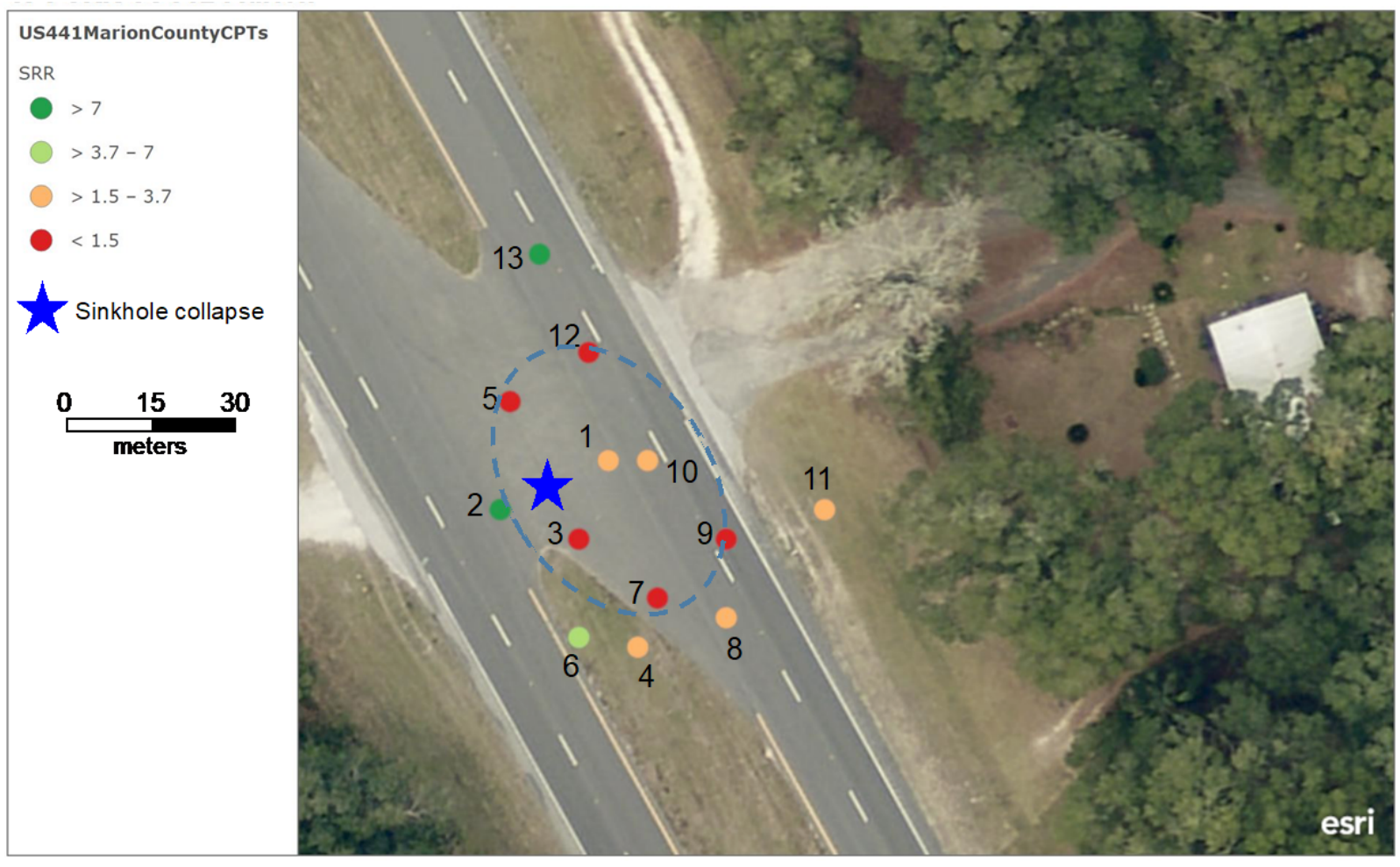

Figure 9. Plots of SRR values at the sinkhole site US 44 1, Marion County

was numbered in the figure. Interestingly, some of locations nearby the surface collapse are not all severely raveled. CPT-2 shows the SRR value greater than 7. This value is similar to CPT-13, which is farthest from the collapse. It is postulated that raveling (or internal erosion) in this site is more localized and the collapse may be due to subsurface soil erosion or piping rather than the growth of single gigantic cavity by which the Winter Park Sinkhole was formed (Jammal 1986). The most severe raveling locations are observed in CPT-3, 5, 9, and 12 , which indicates the influence area of raveling as a dash-line circle in the figure. It is important to note that the surface collapse is not always vertically aligned with the sinkhole source. The sinkhole source, which is the initiation point of cavity growth, is considered as a point of groundwater recharge. Often the raveling progresses as piping channels propagating in a diagonal direction, thus the location of surface collapse can be distant from the sinkhole source.

\section{Numerical Analysis}

The soil stratigraphy of the US 441 site was estimated from CPT-1 sounding data, which exhibits a relatively less raveled condition. It was assumed that the soil condition at CPT-1 represents the in situ state of the site before hurricane Irma and contains the typical amount of raveling expected from a normal central Florida sounding profile. Using Robertson's soil behavior type (SBT) chart (Robertson, 1990), the CPT data showed a soil profile composed of $2 \mathrm{~m}$ of silty sands followed by $6 \mathrm{~m}$ of clayey soils. The sounding terminated at a depth of 8 $\mathrm{m}$ which is assumed to indicate the limestone (bedrock) underlying the overburden soils. The soil profile was implemented into the finite element software PLAXIS2D.

A half-circular void was assumed to evolve at the soilbedrock interface to trigger surface failure. In the FE anlaysis, the effects of cavity growth and raised GWT on the stress field of overburden soil were investigated. In the simulations the radius of the cavity was increased from $0 \mathrm{~m}$ to $2.5 \mathrm{~m}$. The depth of GWT was assumed to be $4 \mathrm{~m}$ from the ground surface (typical in that area), and the analysis was performed at one meter rising increments till reaching the ground surface. Also it is important to note that the anlaysis was conducted under hydrostatic condition. 
Principal effecive stresses at two points, points A (along the vertical centerline of the cavity) and B (4 m away horizontally from point A), were determined (see Figure 10). The stress paths at those points were plotted in MIT's stress space (Wood, 1990). More unstable behavior was shown as the the size of cavity increases. Point A exhibits a stress path towards the failure envelope while point $B$ shows the stress path to the right-diagonal direction. In other words, point A shows an unloadingshearing (i.e., the and point $\mathrm{B}$ shows a loading-shearing behavior. On the other hand, an increase of GWT causes a reduction in the mean effective stress due to an increase in pore water pressure, resulting in the stress path shifted to left at both points A and B. When compared to the effect of increased cavity size, the raised GWT exhibited smaller impact on the stability. According to the results, the rapid increase in the groundwater table may not significantly reduce the mechanical stability but increases the hydraulic gradient (i) around the cavity, which contributes to internal soil erosion and piping.

\section{Summary and Conclusions}

The authors performed an investigation on a sinkhole formed within US 441 in Marion County, resulting from Hurricane Irma in September of 2017. The investigation method includes three approaches: a hydrogeological assessment at regional-scale, a subsurface exploration with CPTs, and a FE-based numerical analyses. Key observations and findings are summarized. First, Irma's impact on sinkhole formation was obvious. A total of 30 sinkholes were formed within two weeks after Irma. Second, CPT sounding data indicates not all collapse-nearby locations have severe raveling; thus, the main triggering mechanism of the US441 sinkhole is likely internal soil "piping" not growth of a single large cavity. Third, the US441 site contains a thick cohesive soil layer. The high precipitation due to Irma caused a rapid increase in GWT of the surficial aquifer but slowly recharge the upper Floridan aquifer; thus, a rapid increase of head difference $(\Delta \mathrm{h})$ between surficial and upper Floridan aquifers may generate an increase of hydraulic gradient $(i)$. This high hydraulic gradient leads to large seepage velocity, which accelerates the internal soil erosion/piping. Fourth, the FE analysis results support that the impact of raised GWT is not as significant as the increased cavity size on the failure of collapse. In summary, it is concluded that the main sinkhole triggering mechanism in the US441 site is a rapid increase in hydraulic gradient (or seepage velocity) rather than the impact of raised GWT on the failure condition of overburden soil. Although the erosion/piping is the predominant mechanism in this site, a thick cohesive overburden soil layer may cause a covercollapse type of sinkhole in the site.

\section{References}

Beck, B.F., 1986. A generalized genetic framework for the development of sinkholes and karst in Florida, USA. Environmental Geology Water Science, 8, 5-18.

Brinkmann R, Parise M, Dye D., 2008. Sinkhole distribution in a rapidly developing urban environment: Hillsborough County, Tampa Bay area, Florida. Engineering Geology. 99:169-184.

Doctor, Daniel \& Young, John., 2013. An Evaluation of Automated GIS Tools for Delineating Karst Sinkholes and Closed Depressions from 1-Meter

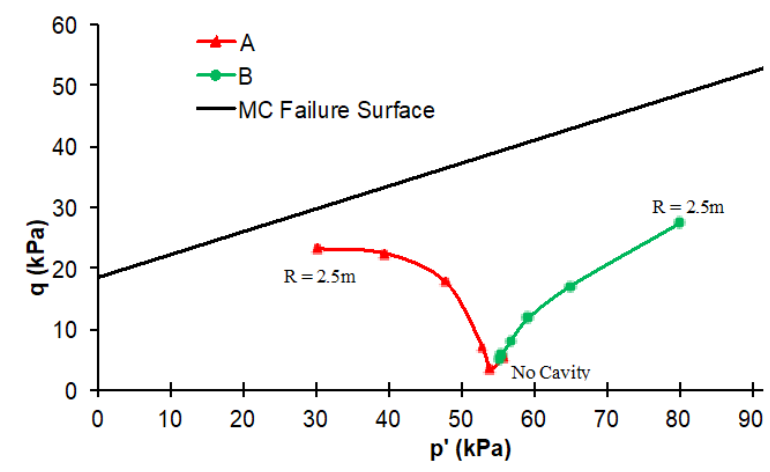

(a)

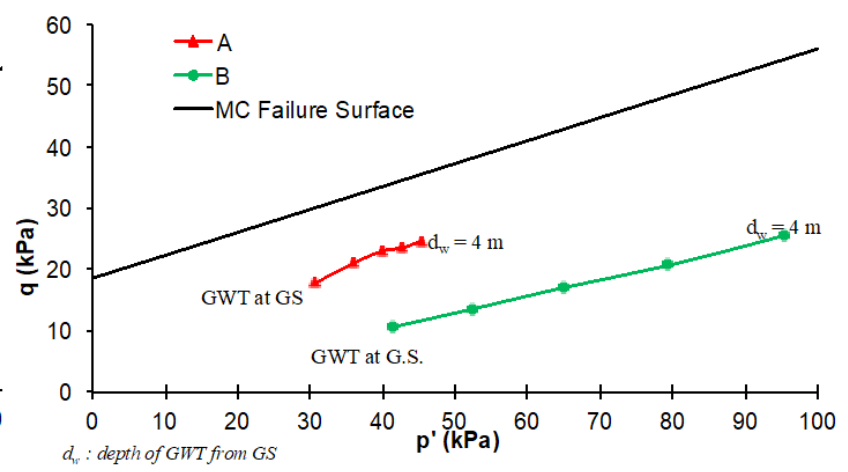

(b)

Figure 10. Results of numerical analysis: stress path change due to (a) cavity size increase and (b) groundwater table rise. 
LiDAR-Derived Digital Elevation Data. 449-458. 10.5038/9780979542275.1156.

Drumm, E.C., Aktürk, Ö., Akgün, H. and Tutluoğlu, L., 2009. Stability charts for the collapse of residual soil in karst. Journal of geotechnical and geoenvironmental engineering, 135(7), pp.925931.

Florida Office of Insurance and Regulation (2010). "2010 Sinkhole Report." Report on Review of the 2010 Sinkhole Data Call, <http://www.floir.com/ siteDocuments/Sinkholes/2010_Sinkhole_Data Call_Report.pdf $>$. (Jun. 12, 2018).

Foshee J, Bixler B., 1994. Cover-subsidence sinkhole evaluation of State Road 434, Longwood, Florida. ASCE, Journal of Geotechnical Engineering 120 (11): 2026-2040.

Gutierrez F, Parise M, De Waele J, Jourde H., 2014. A review on natural and human-induced geohazards and impacts in karst. Earth-Science Reviews. 138:61-88.

Jammal, S.E., 1986. The Winter Park sinkhole and Central Florida sinkhole type subsidence. Proceedings of the Third International Symposium on Land Subsidence, Venice. International Association of Hydrological Sciences, Publication No 151, 585-594.

Kim, Y., Xia, H., Shamet, R., Perez, A., Wang, D., Nam, B. H. (2017), "Sinkhole hazard mapping using probabilistic and statistical models in Central Florida," 2017 Geotechnical Frontiers Conference, March 12-17, Orlando, FL.

Kim, Y., Nam, B. H. (2018), “A comparative study of karst sinkhole hazard mapping using frequency ratio and artificial neural network for each central Florida," The Sinkhole Conference, April 2-6, 2018, Shepherdstown, West Virginia.

Kim, Y., Nam, B., Youn, H., "Sinkhole detection and characterization using LiDAR data with logistics regression (LR)", Remote Sens. 2019, 11(13), 1592.

Kromhout, Clint. (2017). The Favorability of Florida's Geology to Sinkhole Formation. 10.1130/ abs/2017AM-305488.
Kulhawy, F. H., and Mayne, P. W. (1990). "Manual on Estimating Soil Properties for Foundation Design.", Electric Power Research Institute, Palo Alto, California.

Kuniansky, E., Weary, D.J., Kaufmann, J.E., 2015, The current status of mapping karst areas and availability of public sinkhole-risk resources in karst terrains of the United States: Hydrogeology Journal, Online early November 25, 2015, DOI: 10.1007/s10040-015-1333-3, vol. 24, I. 3 pp 613624.

Nam, B. H., Shamet, R., Soliman, M., Wang, D., Yun, H. (2018), "Development of sinkhole risk evaluation program," Project Report, Florida Department of Transportation, Tallahassee, Florida, June 2018. (in press).

National Hurricane Center (2018), National Hurricane Center Tropical Cyclone Report: Hurricane Irma, May 2018.

Perez, A., Nam, B.H, Alrowaimi, M., Chopra, M., Lee, S.-J., Youn, H.-J. (2017a), "Experimental study on sinkhole: soil-groundwater behaviors under varied hydrogeological conditions," Journal of Testing and Evaluation 45, no. 1 (2017): 208-219.

Rahimi, Mina \& Alexander, Calvin., 2013. Locating Sinkholes in LiDAR Coverage of a GlacioFluvial Karst, Winona County, MN. 469-480. 10.5038/9780979542275.1158.

Robertson, P. K. (1990). Soil classification using the cone penetration test. Canadian Geotechnical Journal, 27(1), 151-158.

Shamet, R., Nam, B. H., Horhota, D, (2018) "Development of sinkhole raveling chart based on cone penetration test (CPT) data," The Sinkhole Conference, April 2-6, 2018, Shepherdstown, West Virginia.

Shamet, R., Perez, A., Nam, B. H. (2017), "Sinkhole risk evaluation: detection of raveled soils in Central Florida's Karst geology using CPT," GeoRisk 2017, Denver, Colorado, June 4-7,2017.

Soliman, M., Perez, A., Nam, B. H., Ye, M. (2018) "Physical and numerical analysis on the mechanical behavior of cover-collapse sinkholes in Central Florida," The Sinkhole Conference, April 2-6, 2018, Shepherdstown, West Virginia. 
Soliman, M., Shamet, R. Kim, Y., Nam, B. H., H. Youn (2019), "Numerical investigation on mechanical behavior of sinkhole" Environmental Geotechnics (online published: May 09, 2019). doi.org/10.1680/jenge. 18.00063

Tihansky, A. B. (1999). "Sinkholes, west-central Florida: a link between surface water and ground water. In Land Subsidence in the United States, Galloway, D. L., Jones, D. R., and Ingebritsen, S. E. (eds.). US Geological Survey Circular 1182, $121-40$.

US Geological Survey (2018), National Water Information System: Mapper, https://maps. waterdata.usgs.gov/mapper/index.html (accessed on June 13, 2018)

Waltham, A.; Bell, F.; Culshaw, M., 2005. Sinkholes and subsidence. Chichester: Springer.

Wood, D. M. (1990). Soil behaviour and critical state soil mechanics. Cambridge university press.

Xiao, H., Kim, Y., Nam, B. H, Wang, D. "Investigation of the impact of local-scale hydrogeologic conditions on sinkhole occurrence in East-Central Florida region," Environmental Earth Sciences (2016) 75:1274. 